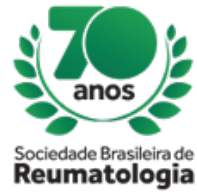

\title{
GLANDERS, A RARE OPORTUNISTIC INFECTION DURING TREATMENT OF RHEUMATOID ARTHRITIS
} WITH RITUXIMAB

Marcus Ivanovith Fernandes (UFCG, Campina Grande, PB, Brasil), Evânia Claudino Queiroga de Figueiredo (UFCG, Campina Grande, PB, Brasil), Maria Angelina Cartaxo F Fernandes (UFCG, Campina Grande, PB, Brasil), Letícia Claudino Queiroga de Figueiredo (UFCG, Campina Grande, PB, Brasil), Daniela Carvalho da Silva (UFCG, Campina Grande, PB, Brasil)

\section{BACKGROUND}

Rheumatoid arthritis (RA) is a chronic, systemic and inflammatory disease, that develops itself in autoimmunity context. The disease and its treatment, with emphasis on biologic therapy, increase the risk of infections in these patients, thus, previous evaluation with sorologies for some infeccious syndromes, besides updating the vaccinal scheme, are measures that may prevent part of these conditions. Glanders is a zoonosis that occurs primarily at solipeds like horses, mules and donkeys, caused by Burkholderia mallei, a Gram-negative bacteria with rare transmition from animals to humans and from humans to humans. It presents initially with ulcerative lesions at the skin and mucous membranes, eventually evolving to chronic, disseminated, pulmonary and septicemia forms.

\section{CASE REPORT}

A 48 year old female patient diagnosed with seropositive RA 17 years before, initially with polyarthritis of hands, wrists and ankles. Treated with methotrexate with good response, then substituted for leflunomide after one year due meaningful elevation of hepatic enzymes. Evolves with good control and after three years presented a new inflammatory outbreak, requiring higher doses of corticosteroids. Adalimumab was then started, with clinical improvement, however after the third month, a severe sinusopathy leaded to the suspension of the anti-TNF. It was introduced, a semiannual scheme with rituximab, evolving with good control of the disease represented by a DAS 28 of 2.2. However, complaining at that period about fever, otalgia and yellowish otorrhea, the patient was referred to an evaluation with an otolaryngologis and after several antibiotics schemes without a proper response, the culture of secretion from the right ear identified the presence of Burkholderia mallei. Therefore, epidemiological investigation revealed that the patient used to work with fertilizers with horse manure at gardening activities few years before. Initiating specific antibiotic therapy, presented a good therapeutic response.

\section{CONCLUSION}

The case presented reported a case of Glanders in a patient with RA, a rare condition, that may had had its expression facilitated by the autoimmune disease or by its treatment. It alerts for the importance of investigating conditions related to rheumatologist diseases, such as opportunistic infections less known and that may compromise the prognosis of immunocompromised patients. 